J. Environ. Sci.

Institute of Environmental Studies and Research - Ain Shams University

\title{
CATALYTIC CRACKING OF HEAVY NAPHTHA USING NEW SULPHONATED MICA CATALYST
}

\author{
Mohammed, M. Abdel Rahim ${ }^{(1)}$; Nadia, Gh. Kandeel ${ }^{(2)}$ \\ and Nabil, A. Negm ${ }^{(3)}$
}

1) North Baharia petroleum company, Cairo, Egypt 2) Faculty of Women for Arts, Ain Shams University 3) Egyptian Petroleum Research Institute, Nasr City, Cairo, Egypt.

\begin{abstract}
Sulphonated mica was prepared as catalytic cracking catalyst for heavy naphtha by sulphonation of oxidized mica using sulfuric acid. The oxidized mica was prepared by the treatment of mica with nitric acid to obtain its oxidized form. The raw mica and the prepared catalyst were analyzed by Xray diffraction and FT-IR spectral analysis. The evaluation of the mica in catalytic cracking reaction of heavy naphtha showed weak activity. Modified mica exhibited high catalytic cracking activity.

Keywords: Heavy Naphtha, Homogenous Catalyst, Oxidation, Catalytic cracking, and Light olefins.

\section{INTRODUCTION}

During petroleum fractionation, crude oil is distillated either by thermal distillation for light components, or vacuum distillation for heavy molecular weight components (heavy cuts). Vacuum distillation is performed for the residuals of the thermal distillation. The main component of the vacuum distillation is the heavy naphtha. Naphtha and reformate are complex mixtures of paraffins, naphthenes, and aromatic in the C5-C12 carbon number. Paraffins or alkanes are saturated aliphatic hydrocarbons of either straight-chain (n-paraffins) or branched structures (iso-paraffins). Olefins or
\end{abstract}


alkenes are unsaturated aliphatic hydrocarbons, and are either straight chains or branched structures, but contain one or more double bonds. Also, in the naphtha range, naphthenes or cycloalkanes are saturated cyclic hydrocarbons that contain at least one ring structure. The most abundant naphthenes found in fossil fuel have ring structures of either five or six carbon atoms. The composition of any naphtha depends on the type of crude oil, boiling range, and whether it is obtained directly from crude oil distillation or produced by catalytic or thermal cracking of heavier oil fractions. Typical straight-run medium naphtha contains 40-70 wt\% paraffins, 20-50 wt\% naphthenes, 5-20 wt $\%$ aromatics, and only 0-2 wt $\%$ olefins. Naphtha produced by fluid catalytic cracking, coking, or vis breaking may contain 30-50 wt\% olefins (Aitani et al., 2000)

Light olefins such as ethylene and propylene are important building blocks for many end products like polyethylene and polypropylene. Recently, market analysis showed that the demand for propylene is outpacing that of ethylene and the current supply cannot match the demand. A large proportion of propylene, about $65 \mathrm{wt} \%$, is produced by steam cracking and about $30 \mathrm{wt} \%$ during the fluid catalytic cracking (FCC) process as a by-product (ShamsiJazeyi., 2010 and Triantafillidis et al.,1999). The propylene to ethylene ratio produced by steam cracking of naphtha is about 0.6 , whereas the ethylene and propylene yields are about 2 and six wt $\%$ from the conventional FCC process. During catalytic cracking, the heavier and more complex hydrocarbon molecules are broken down into simpler and lighter 
molecules by the action of heat and catalyst. It is through this way that heavy oils can be upgraded into lighter and more valuable

products (light olefins, gasoline, and middle distillate components). The FCC is one of the most catalytic cracking technologies used widely in a refinery for producing gasoline and diesel. However, the current direction is to maximize olefins such as propylene and butylene by the addition of zeolite (ZSM-5) to the catalyst formulation (Zhu et al., 2013)

Muscovite mica is the substrate of choice for an ever-increasing variety of experiments involving surfaces. Historically, studies of epitaxial crystal growth on mica go back at least to the first half of the nineteenth century (Christenson et al., 2016) and contact angle measurements of liquids on mica were also reported data in very early stage (NEESEN et al., 1884). Naphtha is transformed into reformates through catalytic reforming process which requires the reconstruction of low-octane hydrocarbons in the petroleum naphtha into more valuable high octane gasoline components. In this study, sulphonated mica, a heterogeneous catalyst, was prepared and characterized using infrared spectroscopy (FTIR) and X-ray diffraction (XRD). The prepared catalyst was evaluated in catalytic cracking of heavy naphtha obtained from vacuum distillation of crude oil residues. Parameters influencing the catalytic conversion reaction of the heavy naphtha are investigated. The catalyst activity was correlated to its chemical structure. 


\section{EXPERIMENTAL}

1. Materials: Mica from Sigma, nitric acid (HNO3), sulfuric acid (H2SO4) and heavy naphtha from Sigma were purchased from Sigma-Aldrich, UK and were used as-received without further purification.

2. Preparation of Sulfonated Catalyst: Two steps were performed to synthesize Mica-SO3H catalyst: the first step is oxidation of mica by nitric acid. In a typical reaction, $1 \mathrm{~g}$ of mica was treated with $10 \mathrm{~mL}$ of concentrated HNO3 (13.9 M) at $353 \mathrm{oK}$ until dryness, and the residue was washed with distilled water until all the nitrates were removed (Pradhan et al.; 1999) The commercial mica oxidized by nitric acid is referred as Nitric Mica (NM). The second step is acid functionalization of oxidative mica by sulfuric acid (Mica-SO3H). In a typical reaction, $5 \mathrm{~g}$ of oxidized mica was mixed with $100 \mathrm{ml}$ of concentrated $\mathrm{H} 2 \mathrm{SO} 4$ and heated at $155 \mathrm{oC}$ in a nitrogen atmosphere reflux and stirring for $12 \mathrm{~h}$. The sulfonated mica was filtered and washed several times using deionized water and dried at 100 oC for $24 \mathrm{~h}$ to obtain sulfonated mica (NM-SO3H).

3. Characterizations of the prepared Catalyst: The texture properties of mica and its sub-derived composite material were examined using both HR-transmission electron microscope (HR-TEM) and BET surface area analyzer. Before subjecting to the microscope, all samples were subjected to sonication into ethanol for $10 \mathrm{~min}$ to get homogenously dispersed particles. On the other hand, the mica and the functionalized material were subjected to BET analyzer to determine their 
Surface area and total pore-volume. Thermal stability of the produced materials was also measured using thermal gravimetric analyzer (TGA-DSC) equipment. The structure and crystallinity nature of the obtained materials during this research work was also confirmed via X-Ray diffraction (XRD) analysis. The functional groups of the mica-based structures were determined using Fourier Transform Infra-red (FT-IR). The surface morphology of the mica and mica/SO3H were investigated by the scanning electron microscope (SEM).

4.1 X-Ray Diffraction (XRD): X-ray powder diffraction (XRD) patterns had been recorded on a Brucker AXS-D8 Advance (Germany) by using nickelfiltered copper radiation $(\lambda=1.5405 \AA)$ at $30 \mathrm{Kev}$ and $40 \mathrm{~mA}$ with a scanning speed of $4^{\circ}$ min- 1 over diffraction angle range.

4.2 Fourier Transform Infra-Red (FT-IR): FT-IR spectra of the freshlymade material recorded on ATI Mattson Genesis series ( $\mathrm{KBr}$ disc method) apparatus, Model 960 M009 series.

4.3 Catalytic Activity: A high pressure micro fixed bed reactor unit - down flow (cata-test unit) that consists of a stainless steel reactor (internal diameter $19 \mathrm{~mm}$, external diameter $27 \mathrm{~mm}$, and length $50 \mathrm{~cm}$ ) has been used. It is divided into three zones, each is heated and separately temperature controlled.50 $\mathrm{cc}$ of the catalyst is charged in the middle zone of the reactor. The conversion reactions of the feed stock were carried out at reaction temperature ranges of $300-400 \mathrm{oC}$.

4.4 Gas chromatography: Representative liquid are samples collected and analyzed by Gas chromatography (GC) model (Agilent 7890) equipped 
with (FID) and (TCD) detectors using PIONA and DC-200 columns for liquid and gas samples, respectively.

\section{RESULTS AND DISCUSSION}

\section{1) Characterization:}

1.1 X-ray Diffraction: The powder X-ray diffraction patterns of raw mica and sulphonated mica catalyst are shown in figure 1 . It was noted that the characteristic diffraction peaks showed at $2 \theta=8.8^{\circ}, 17.7^{\circ}, 26.7^{\circ}, 35.9^{\circ}$, $41.5^{\circ}, 45.4^{\circ}, 55.1^{\circ}, 64.4^{\circ}$ and they were well indexed to the mica (ICDD Card No. 16-0344) crystallographic planes of monoclinic muscovite-2M1 (JCPDS No. 46-1409), respectively (Ramirez et al.; 2003). The characteristic mica XRD patterns are retained in the XRD patterns of the sulfonated mica framework, which showed the stability of the formed framework compared to mica clay itself.

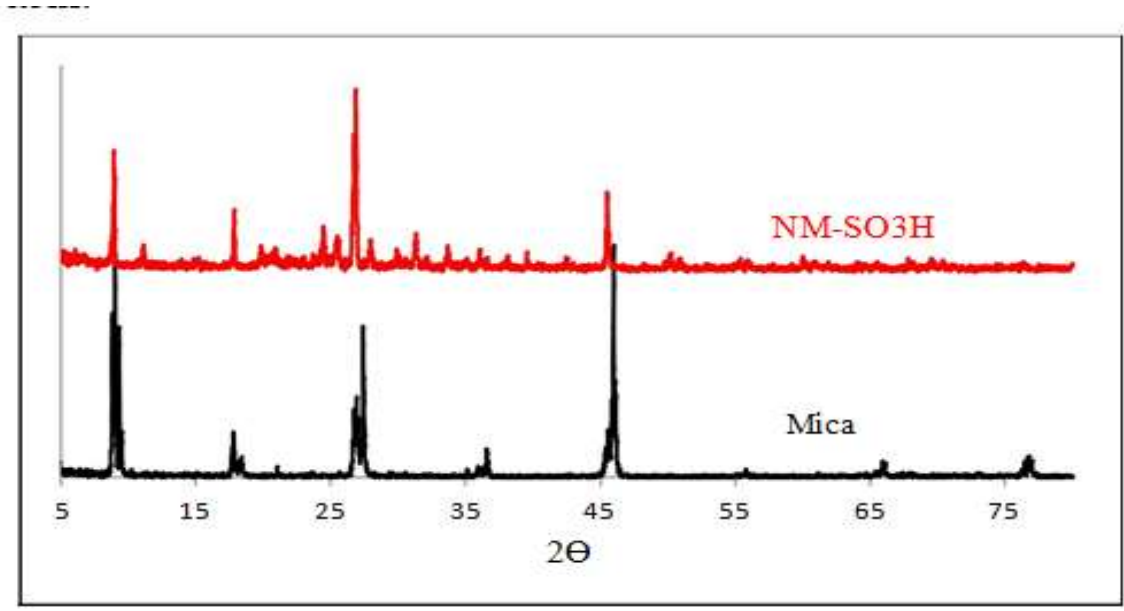

Figure (1): XRD spectra of raw Mica and NM-SO3H 
1.2 Fourier Transform Infra-Red (FT-IR): FT-IR analysis was used to investigate variations in the functional groups of the mica and the functionalized mica structures. FTIR technique is a useful analytical method which can provide sharp tracking for the changes in the structure through the increase and decreases in the intensity of the detected peaks. The FT-IR spectroscopic study of both the raw mica, oxidative mica, and sulphonated mica are presented in Fig 2. The characteristic absorption bands at 3426 and $1629 \mathrm{~cm}-1$ represent asymmetrical stretching and bending vibrations of $\mathrm{OH}$ group, respectively. The characteristic peak at $1710 \mathrm{~cm}-1$ is assigned to the $\mathrm{C}=\mathrm{O}$ group and the absorption bands at 2984 and $2898 \mathrm{~cm}^{-1}$ are assigned for asymmetrical and symmetric stretching vibrations of $\mathrm{C}-\mathrm{H}$ groups. Si-O-Al bending along with $\mathrm{Mg}-\mathrm{OH}$ is located at $687 \mathrm{~cm}-1$. The peak at $972 \mathrm{~cm}-1$ represents the bending vibration modes due to the $\mathrm{Al}-\mathrm{AlOH}$, while the rocking band at $459 \mathrm{~cm}-1$ is due to the presence of quartz silica (ShamsiJazeyi et al., 2010). Fig 2 showed a significant difference in FTIR spectra in the range of 1300-1700 cm-1 related to the surface functional groups of $\mathrm{NM}$ and raw mica. The absorption band at $1620 \mathrm{~cm}-1$ represented in the spectrum for raw mica, while it has been weakened in NM. This band represents quinone functional groups (Tukur et al.,2005). Briefly, due to nitric acid treatment, the quinone functional groups were reduced from the raw mica. It was attractive to investigate the possibility of formation of some nitrogen functionalities on the carbon surface during acid treatment with nitric acid. 


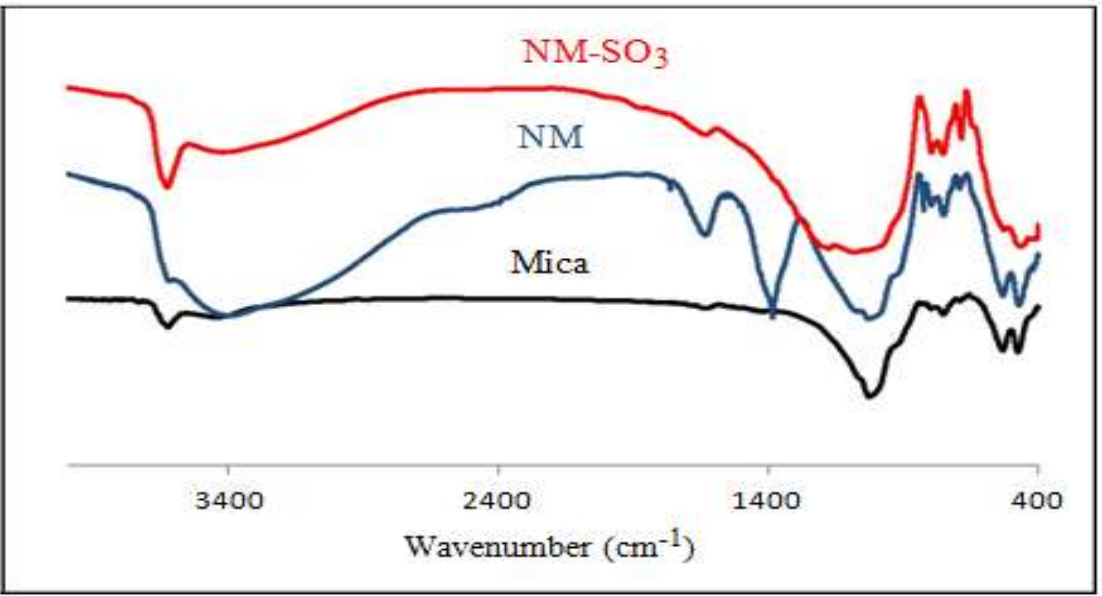

Figure (2): FTIR spectra of raw Mica, NM and NM-SO3H

1.3 Catalytic Cracking of Heavy Naphtha: The heavy naphtha cracking reaction is used to evaluate the acidity of the prepared samples. The catalytic activity of solid acid catalysts is not only related to the surface concentration of acid sites but also their nature, that is being Lewis or Brønsted sites (Tyagi et al., 2006). The heavy naphtha cracking is a model reaction for identifying the Lewis and Brønsted acid sites present in a catalyst.

2.1 Dodecane cracking: The results of dodecane cracking over mica and $\mathrm{NM}-\mathrm{SO} 3 \mathrm{H}$ as a function of temperature are presented in Table 1 and Fig. 3. These results indicate that significant cracking of dodecane occurred over mica and catalyst. As shown in Table 1, the mica shows a very low catalytic activity at all temperatures for dodecane cracking due to a week of acidity. NM-SO3H shows high 
catalytic activity for dodecane cracking $(55.54,73.18,80.11,89.31$, and $88.20)$ at $(300,325,350,375$ and 400$)$ respectively. This can be attributed to the low critical diameter of dodecane $(0.49 \mathrm{~nm})$ which poses no diffusion limitations even in NM-SO3H. It has been reported that strong acid sites are needed for n-dodecane cracking (Abul-Hamayel et al., 2005).

Table (1): Cracking conversion \% of Dodecane over Mica and NM-SO3H at different temperatures

\begin{tabular}{|c|c|c|c|c|c|c|}
\hline Temperature, oC & $\mathbf{3 0 0}$ & $\mathbf{3 2 5}$ & $\mathbf{3 5 0}$ & $\mathbf{3 7 5}$ & $\mathbf{4 0 0}$ \\
\hline Materials & \multicolumn{5}{|c|}{ Conversion \% } \\
\hline Mica & 15.22 & 18.32 & 22.10 & 23.26 & 23.84 \\
\hline NM-SO3H & 55.54 & 73.18 & 80.11 & 89.31 & 88.20 \\
\hline \hline \\
\hline
\end{tabular}

Figure (3): Variation of conversion \% of Dodecane over Mica and NMSO3H Catalyst.

2.2.Iso-Octane Cracking: The results of iso-octane cracking over both mica and $\mathrm{NM}-\mathrm{SO} 3 \mathrm{H}$ as a function of temperature are presented in Fig 4 and Table 2. These results indicate that there was almost very weak cracking of iso-octane at all temperature over mica. This can be attributed to the higher critical diameter of iso-octane which poses severe diffusion limitations (Degnan et al., 2000). The highest conversion of iso-octane was observed 
over NM-SO3H catalyst at all temperatures due to a high acid sites on the catalyst.

Table (2): Cracking conversion \% of Iso-Octane over Mica and NM- SO3H at different temperatures

\begin{tabular}{|c|c|c|c|c|c|}
\hline Temperature, $\mathbf{o C}$ & $\mathbf{3 0 0}$ & $\mathbf{3 2 5}$ & $\mathbf{3 5 0}$ & $\mathbf{3 7 5}$ & $\mathbf{4 0 0}$ \\
\hline \hline Materials & \multicolumn{5}{|c|}{ Conversion \% } \\
\hline Mica & 12.11 & 14.32 & 16.43 & 17.65 & 17.11 \\
\hline NM-SO3H & 60.38 & 65.12 & 68.11 & 74.00 & 75.23 \\
\hline
\end{tabular}

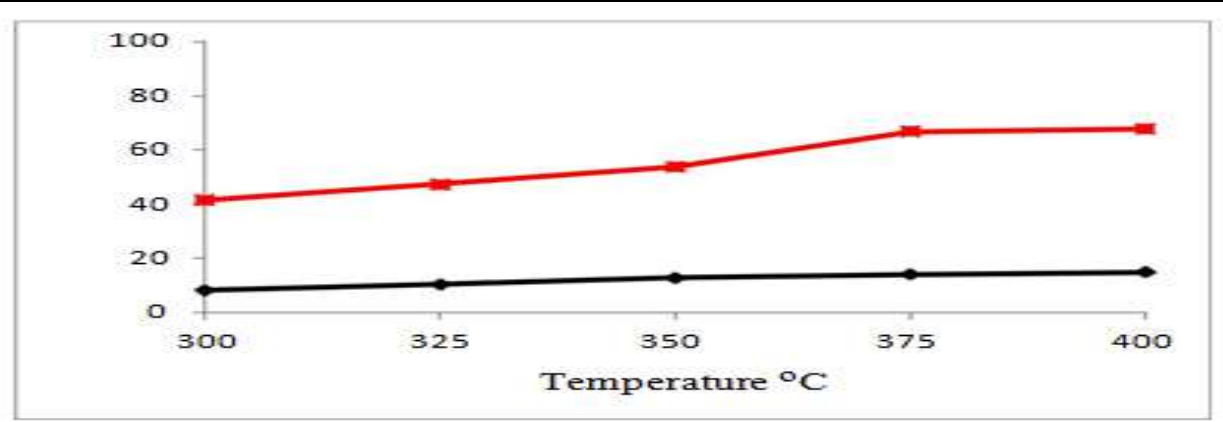

Figure (4): Variation of conversion \% of Iso-Octane over Mica and NMSO3H Catalyst.

2.3 Ethyl Benzene Cracking: The results of ethyl benzene cracking over mica and $\mathrm{NM}-\mathrm{SO} 3 \mathrm{H}$ as a function of temperature are presented in Fig 5 and Table 3. These results indicate that there was almost surely week cracking of ethyl benzene at all temperatures over mica. This can be attributed to the higher critical diameter of ethyl benzene $(0.56 \mathrm{~nm})$ than mica which poses severe diffusion limitations in order to weekly of the acid site on mica (Zhao et al., 1999). The highest conversion of ethyl benzene was observed over NM-SO3H catalyst possibly due to diffusion limitation in its catalyst component and high acidity. 
Table (3): Cracking conversion \% of Ethyl Benzene over Mica and NM$\mathrm{SO} 3 \mathrm{H}$ at different temperatures

\begin{tabular}{|c|c|c|l|l|l||}
\hline Temperature, oC & $\mathbf{3 0 0}$ & $\mathbf{3 2 5}$ & $\mathbf{3 5 0}$ & $\mathbf{3 7 5}$ & $\mathbf{4 0 0}$ \\
\hline \hline Materials & \multicolumn{5}{|c|}{ Conversion \% } \\
\hline Mica & 8.14 & 10.35 & 12.73 & 14.05 & 14.91 \\
\hline NM-SO3H & 41.57 & 47.31 & 53.87 & 66.85 & 67.81 \\
\hline
\end{tabular}

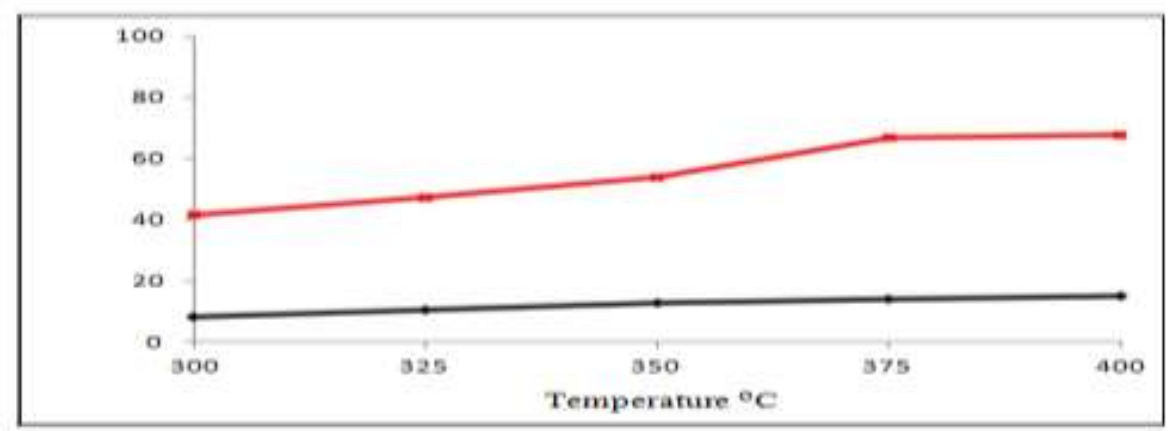

Figure (5): Variation of conversion \% of Ethyl Benzene over Mica and NMSO3H Catalyst.

\section{CONCLUSION}

The present work reports on a heterogeneous catalyst involving both the proper control of the surface chemistry and rigorous control of high acidic functional groups. The oxidation mica is successfully prepared with nitric acid to increasing of a hydroxyl group. The sulfonyl group was grafted on mica with sulfuric acid to acidification of oxidized mica For the Residue of Crude Oil and its treatment. The activity of NM-SO3H catalyst was higher than pure mica for heavy naphtha cracking at all temperatures. The highperformance catalytic activity of the prepared catalyst is related to high acidity. 


\section{REFERENCES}

Abul-Hamayel, M. A.; Aitani, A. M.; and Saeed, M. R.(2005): Enhancement of Propylene Production in a Downer FCC Operation using a ZSM-5 Additive. Chemical Engineering \& Technology: Industrial Chemistry-Plant Equipment-Process Engineering-Biotechnology, 28(8), 923-929.

Aitani, A.; Yoshikawa, T.; and Ino, T.(2000): Maximization of FCC light olefins by high severity operation and ZSM-5 addition. Catalysis Today, 60(1-2), 111-117.

Akah, A.; and Al-Ghrami, M.(2015): Maximizing propylene production via FCC technology. Applied Petrochemical Research, 5(4), 377-392.

Arandes, J. M.; Torre, I.; Azkoiti, M. J.; Erena, J.; Olazar, M.; and Bilbao, J. (2009): HZSM-5 zeolite as catalyst additive for residue cracking under FCC conditions. Energy \& Fuels, 23(9), 4215-4223.

Askari, A.; Karimi, H.; Rahimi, M. R.; and Ghanbari, M.(2012): Simulation and modeling of catalytic reforming process. Petrol. Coal, 54(1), 76-84.

Bhasin, M. M.; McCain, J. H.; Vora, B. V.; Imai, T.; and Pujado, P. R.; (2001): Dehydrogenation and oxydehydrogenation of paraffins to olefins. Applied Catalysis A: General, 221(1-2), 397-419.

Choudhary, V. R.; and Akolekar, D. B: Comparison between catalytically important zeolites for their catalytic properties and deactivation. Journal of Catalysis, 125(1), 143-156, (1990).

Christenson, H. K.; and Thomson, N. H.(2016): The nature of the air-cleaved mica surface. Surface Science Reports, 71(2), 367-390.

Corma, A.; Melo, F.; Sauvanaud, L.; and Ortega, F. J.(2004): Different process schemes for converting light straight run and fluid catalytic cracking naphthas in a FCC unit for maximum propylene production. Applied Catalysis A: General, 265(2), 195-206.

Degnan, T. F.; Chitnis, G. K.; and Schipper, P. H.(2000): History of ZSM-5 fluid catalytic cracking additive development at Mobil. Microporous and Mesoporous materials, 35, 245-252. 
Hollander, M. A.; Wissink, M.; Makkee, M.; and Moulijn, J. A.(2002): Gasoline conversion: reactivity towards cracking with equilibrated FCC and ZSM-5 catalysts. Applied Catalysis A: General, 223(1-2), 85-102.

Elsayed, H. A.; Menoufy, M. F.; Shaban, S. A.; Ahmed, H. S.; and Heakal, B. H.(2017): Optimization of the reaction parameters of heavy naphtha reforming process using $\mathrm{Pt}-\mathrm{Re} / \mathrm{Al} 2 \mathrm{O} 3$ catalyst system. Egyptian Journal of Petroleum, 26(4), 885-893.

Gil, A.; Gandia, L. M.; and Vicente, M. A.(2000): Recent advances in the synthesis and catalytic applications of pillared clays. Catalysis Reviews, 42(1-2), 145-212.

Hyde, B.(2012): Light olefins market review. Foro Pemex Petroquimica, Mexico.

Kaur, S.; Singh, S.; and Singh, L.(2017): Effect of oxygen ion irradiation on dielectric, structural, chemical and thermoluminescence properties of natural muscovite mica. Applied Radiation and Isotopes, 121, 116-121.

Lee, J.; Hong, U. G.; Hwang, S.; Youn, M. H.; and Song, I. K.(2013): Catalytic cracking of C5 raffinate to light olefins over lanthanumcontaining phosphorous-modified porous ZSM-5: Effect of lanthanum content. Fuel processing technology, 109, 189-195.

Christenson, H. K.; and Thomson, N. H.(2016): The nature of the air-cleaved mica surface. Surface Science Reports, 71(2), 367-390.

Moreno-Castilla, C.; Ferro-Garcia, M. A.; Joly, J. P.; Bautista-Toledo, I.; Carrasco-Marin, F.; and Rivera-Utrilla, J.(1995): Activated carbon surface modifications by nitric acid, hydrogen peroxide, and ammonium peroxydisulfate treatments. Langmuir, 11(11), 4386-4392.

NEESEN, D. F.(1884): DIE FORTSCHRITTE DER PHYSIK IM JAHRE 1878 .

Pradhan, B. K.; and Sandle, N. K.(1999): Effect of different oxidizing agent treatments on the surface properties of activated carbons. Carbon, 37(8), 1323-1332. 
Ramirez, A.; Lopez, B. L.; and Sierra, L.: Study of the acidic sites and their modifications in mesoporous silica synthesized in acidic medium under quiescent conditions. The Journal of Physical Chemistry B, 107(35), 9275-9280, (2003).

ShamsiJazeyi, H.; and Kaghazchi, T.: Investigation of nitric acid treatment of activated carbon for enhanced aqueous mercury removal. Journal of Industrial and Engineering Chemistry, 16(5), 852-858, (2010).

Triantafillidis, C. S.; Evmiridis, N. P.; Nalbandian, L.; and Vasalos, I. A. (1999): Performance of ZSM-5 as a fluid catalytic cracking catalyst additive: effect of the total number of acid sites and particle size. Industrial \& engineering chemistry research, 38(3), 916-927.

Tukur, N. M.; and Al-Khattaf, S.(2005): Catalytic cracking of n-dodecane and alkyl benzenes over FCC zeolite catalysts: time on stream and reactant converted models. Chemical Engineering and Processing: Process Intensification, 44(11), 1257-1268.

Tyagi, B.; Chudasama, C. D.; and Jasra, R. V.(2006): Determination of structural modification in acid activated montmorillonite clay by FT-IR spectroscopy. Spectrochimica Acta Part A: Molecular and Biomolecular Spectroscopy, 64(2), 273-278.ISO 690 hydrogen.

Zhao, X.; and Roberie, T. G.(1999): ZSM-5 additive in fluid catalytic cracking. 1. Effect of additive level and temperature on light olefins and gasoline olefins. Industrial \& engineering chemistry research, 38(10), 3847-3853.

Zhu, Y.; Zhou, Y.; Utama, M. I. B.; de la Mata, M.; Zhao, Y.; Zhang, Q.; and Xiong, Q.(2013): Solution phase van der Waals epitaxy of $\mathrm{ZnO}$ wire arrays. Nanoscale, 5(16), 7242-7249. 
J. Environ. Sci.

Institute of Environmental Studies and Research - Ain Shams University

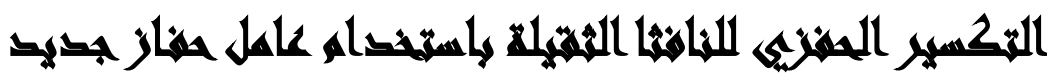

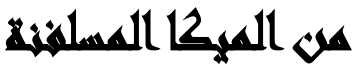

\section{[}



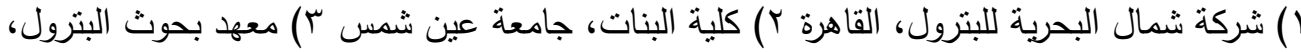
القاهرة

\section{المستخلي}

في هذا البحث نم تحضير عامل حفاز من الميكا عن طريق تفاعلها في صورتها المتأكسدة مع الكعاء

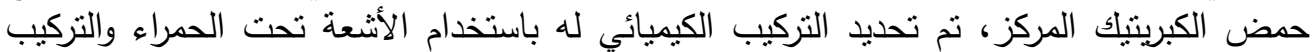

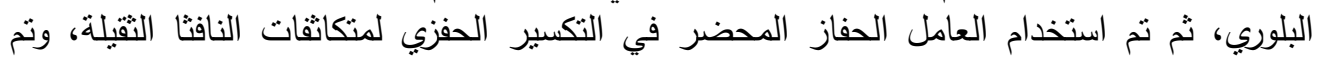
مقارنة ناتج التكسير باستخدام الميكا غير المعدلة والميكا المعدلة. أظهرت النتائج كفاءة العامل الحفاز المحضر في عملية تكسير المكونات ذاتير ذات النسب الأكبر في

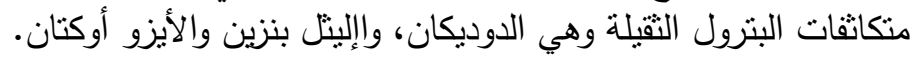

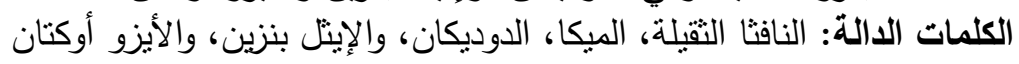

